\title{
A NEW METHOD FOR PROJECT RANKING BASED ON RISK MANAGEMENT AND MULTICRITERIA APPROACH
}

\author{
Mahdi Nakhaeinejad
}

\begin{abstract}
Department of Industrial Engineering, Yazd University, Yazd, Iran
\end{abstract}

Received: 27 May 2020

Revised: 22 June 2020

Accepted: 27 July 2020

\begin{abstract}
Project portfolio selection and projects ranking represent difficult decisions in organizations due to many factors. One of the most important of these factors is varying levels of projects risk. The manager has many alternative projects to pursue and the objective is to minimize total risk of projects. In this paper, an organized framework for project portfolio selection presented through a new method based on Failure Mode and Effect Analysis (FMEA), Shannon Entropy approach (SEA), and Technique of Order Preference Similarity to the Ideal Solution (TOPSIS). The project ranking method proposed in this paper is a technique for organizations to rank the projects and select the best candidate by multi-criteria approach. The FMEA is used to analyze project risks. The Risk Priority Number (RPN) are determined as the criteria and their weights calculated by SEA. Finally, TOPSIS method is used to set final ranking. To measure the usability and quality of the proposed method a typical project ranking problem is presented. The results reveal that the proposed method can effectively be used for project ranking.
\end{abstract}

Keywords: Project portfolio selection, FMEA, Shannon, Entropy, TOPSIS.

\section{INTRODUCTION}

Project portfolio selection and projects ranking is a difficult problem with more than one dimension and more than one decision maker (Buchanan, \& Vanderpooten, 2007). One of the most important factors should be considered for projects ranking is the risk of delivering projects. Risks are threats for project delivering. Failure to consider risks adequately in projects caused higher costs and time (Taylan, Bafail, Abdulaal, \& Kabli, 2014). FMEA model is one of the techniques used to evaluate the project risks. This paper aimed to propose a new method combining FMEA, SEA and TOPSIS technique to rank and then select projects based on risk management of projects delivering. The proposed method is applied to determine the preference of projects versus risk criteria of projects delivering.

For risk evaluation, the FMEA method considers three kinds of attributes, namely, occupancy, detectability, and severity. Occupancy is the probability of the risk, detectability is the ability of detect risk, and severity is applied as severity of the risk effect. The RPN is established to assess the potential failure modes of a project by multiplying indicators of occupancy, detectability, and severity. The judgment about indicators are proposed by experts (Vahdani, Salimi, \& Charkhchian, 2015).

TOPSIS is a ranking method attempts to choose alternatives that simultaneously have the shortest distance from the positive ideal

Corresponding author. Email: m.nakhaeinejad@yazd.ac.ir

ISSN 2560-4961 (online)

Copyright $(\odot) 2020$, The Authors. Published by IPMA Serbia.

This is an open access article under the CC BY-NC 4.0 license (https://creativecommons.org/licenses/bync/4.0/)

doi: $10.18485 /$ epmj.2020.10.1.6 
solution and the farthest distance from the negative ideal solution (Selim, Yunusoglu, \& Yilmaz, 2016). Some advantages of TOPSIS are simple to use, consider all types of criteria (subjective and objective), rational and understandable, straightforward the computation processes, permit the pursuit of best alternative criterion, depicted in a simple mathematical form, ability to identify the best alternative quickly (Vahdani et al., 2015).

This study aimed to propose a new method of FMEA combining SEA, and TOPSIS method for ranking projects in order to reduce the risk of selected projects. For project ranking, many approaches have been suggested in the literature. Goletsis, Psarras and Samouilidis (2003) developed a hybrid technique for project ranking by ELECTRE III and PROMETHEE methods. They presented an experience of the application of their methodology for project ranking in the Armenian energy sector. Buchanan and Vanderpooten (2007) developed a project selection methodology which incorporates the ELECTRE III decision support tool for Mighty River Power, a New Zealand electricity generator. Mahmoodzadeh, Shahrabi, Pariazar and Zaeri (2007) proposed a new method for project selection problem using fuzzy AHP and TOPSIS technique. They calculate weight of each criterion by improved AHP by Fuzzy set theory and assess projects by implementing TOPSIS algorithm. Pakdin (2010) proposed a new methodology to assess alternative projects and help the decision-maker to select the best one for National Iranian Oil Company by using six criteria of comparing investment alternatives in an AHP and fuzzy TOPSIS techniques. They used AHP to analyze the structure of the project selection problem and weights of the criteria, and they used fuzzy TOPSIS method to obtain final ranking. Daneshvar and Erol (2012) presented the fuzzy ELECTRE approach for ranking the most effective projects. They explained a real-life example in the construction sector with respect to four criteria and four decision makers. Yazdani-Chamzini, Haji and Mahmoodian (2013) employed the fuzzy ELECTRE method for ranking risk of tunnel construction projects and used their proposed model in a real-world case study, Tehran's line 7 subway project.
Samaras, Gkanas and Vitsa (2014) assessed risk in the dam projects with the use of two multicriteria methods, AHP and ELECTRE I, in the Prefecture of Trikala (Greece). Their findings of both methods show a complete and detail view of the risks that the constructor and the supervisor must focus in their future inspections. Mandić, Jovanović and Bugarinović (2014) presented an original twophase model for ranking rail way projects for ranking 75 Serbian Railways projects. Taylan et al. (2014) proposed hybrid methodologies that applied the relative importance index method to prioritize the project risks. They categorized the construction projects by fuzzy AHP and fuzzy TOPSIS methodologies. They used Fuzzy AHP to create weights for fuzzy linguistic variable of construction projects overall risk and the fuzzy TOPSIS method for solving group decision making problems under the fuzzy environment. Vahdani et al. (2015) proposed a new FMEA model combining TOPSIS and belief structure. They combined the fuzzy belief TOPSIS method with FMEA to introduce a belief structure FMEA to describe the expert knowledge by a number of linguists as a grammatical phenomenon. Tavana, Keramatpour, Santos-Arteagad and Ghorbaniane (2015) proposed a three-stage hybrid method for selecting an optimal combination of projects. They used Data Envelopment Analysis (DEA) for the initial screening, the TOPSIS for ranking the projects, and linear Integer Programming (IP) for selecting the most suitable project portfolio in a fuzzy environment according to organizational objectives. Carbone and Tippett (2004) proposed the extension of FMEA format to quantify and analyze project risks. They modified the detection value of the standard FMEA for use in the project environment. They illustrated their approach in a case study of electronics industry. Walczak and Rutkowska (2017) proposed a fuzzy technique for order preference based on the similarity to an ideal solution for the personalized ranking of projects in a participatory budget. A participatory budget is a group decision making process where citizens distribute public resources among a set of city investment proposals. They described the application of fuzzy TOPSIS with a modification for participatory budget based on an empirical example from Poland. Pérez, 
Gómez, Caballero and Liern (2018) proposed a mathematical model for selecting and implementing project portfolios through the use of fuzzy parameters. Their model combines selecting and planning project portfolios and specifies different relationships between projects (synergies, incompatibilities, time order, etc.). Li, Wang, Yan and Zhao (2018) developed a mean-variance mixed integer nonlinear optimal selection model to deal with the uncertain dynamic project portfolio selection problem with divisibility. Cesarone, Scozzari and Tardella (2019) provided new theoretical results for the Risk Parity approach for general risk measures. They proposed a novel framework for portfolio selection that combines the diversification and the optimization approaches through the global solution of a hard nonlinear mixed integer or pseudo Boolean problem. For the latter problem they proposed an efficient and accurate Multi-Greedy heuristic that extends the classical single-threaded greedy approach to a multiple-threaded setting. Oukil and Govindaluri (2020) developed a hybrid multi attribute decision-making methodology for ranking project proposals through a judicious usage of historical data of completed projects to determine attribute weights, enabling elimination of problems associated with projected data such as cost and schedule overruns of real-world projects. Won and Kim (2020) considered robust mean-variance portfolio selection involving a trade-off between the worst-case utility and the worstcase regret, or the largest difference between the best utility achievable under the model and that achieved by a given portfolio. They proposed an iterative algorithm based on the cutting-set method for the problem. Puerto, Rodríguez-Madrena and Scozzari (2020) proposed a Mixed-Integer Linear Programming formulation for clustering and portfolio selection problems in a unified phase. They measure the effect of clustering on the selected assets with respect to the non-selected ones by adding a new criterion to the portfolio selection problem based on an objective function of a classical location problem. Ma, Harstvedt, Jaradat and Smith (2020) studied project selection from the perspective of sustainability in an uncertain decision-making environment. They used a fuzzy logic model based on the TOPSIS approach to incorporate sustainability under uncertainty to obtain the most sustainable solution.

This study is different from the previous research through developing a new method based on FMEA, SEA, and TOPSIS for project ranking. More specifically, this study contributes to the way of combining these three methods that makes the proposed method straightforward and effective for project ranking framework that can be easily implemented. Additionally, this study uses important criteria for the risk management in project ranking such as 'severity', 'probability', and 'detection' in the areas of 'time', 'cost', and 'quality' of projects. To confirm the viability of the proposed framework, a numerical example is implemented. The projects are evaluated in terms of the proposed criteria by utilizing proposed method of combining FMEA, SEA, and TOPSIS method.

The remaining of this paper is organized as follows. The FMEA method, TOPSIS method and SEA are explained briefly in the next section, respectively. In Sect. 3, the proposed project selection framework based on FMEA, TOPSIS, and SEA are presented as new method. In Sect. 4, a numerical example is provided to illustrate the process of the proposed method step by step for project portfolio selection and projects ranking. The last section is devoted to conclusion.

\section{FMEA, TOPSIS, and SEA}

In this paper, FMEA is integrated with SEA and TOPSIS technique by using RPN of risks as a criterion in determining ranking of projects. In the proposed method, FMEA computes the RPN related to time, cost and, quality of each project. Then, the SEA is used to obtain the relative importance of evaluation criteria. Finally, TOPSIS method computes the final ranking order of projects.

\subsection{FMEA method}

FMEA is a step-by-step approach for failure modes and effects analysis. This method identifies the potential failure and its effects. In order to rank the failure, an aggregated index has been applied based on three indicators of 
$1-10$, related to severity $(S)$, occurrence $(O)$, and detection (D) (Vahdani et al., 2015).

For each failure mode, the numerical value of RPN should be calculated. The RPN is obtained by multiplying the three numerical value $(S, O, D)$ ratings:

$$
R P N=(S) *(O) *(D)
$$

There is 1 to 10 score for each of occurrence, detection, and severity.

- Severity: $1=$ not severe, $10=$ very severe

- Occurrence: $1=$ not likely, $10=$ very likely

- Detection: $1=$ easy to detect, $10=$ not easy to detect

By multiplying the numerical values of the three factors $(S, O$, and $D)$, an RPN will be determined for each potential failure mode and effect. The RPN that range from 1 to 1000 for each failure mode is used to rank the corrective actions for eliminating or reducing the potential failure modes (Toljaga-Nikolić, Todorović, \& Bjelica, 2018). Those failure modes with the highest RPNs should be attended first. Some major advantages of FMEA are systematic structure, connections between reasons and effects, and takes into account the failure severity (Selim et al., 2016).

\subsection{TOPSIS method}

The "Technique for Order Preference by Similarity to Ideal Solution" (TOPSIS) is considered as a multi criteria decision analysis method. The method is based on the idea that the best alternative should have as short as possible geometric distance from the positive ideal solution (PIS) and maintains as long as possible geometric distance from the ideal negative solution (NIS). In fact, this method minimizes the distance to the ideal alternative while maximizing the distance to the worst one (Vahdani et al., 2015; Walczak \& Rutkowska, 2017). The TOPSIS process is conducted as follows.

Step 1: Decision matrix construction.

Evaluation matrix, with $m$ alternatives and $n$ criteria is prepared as follows:

$$
\left(\begin{array}{cccc}
x_{11} & x_{12} & \cdots & x_{1 n} \\
x_{21} & x_{22} & \cdots & x_{2 n} \\
\vdots & \vdots & \cdots & \vdots \\
x_{m 1} & x_{m 2} & \cdots & x_{m n}
\end{array}\right)
$$

The intersection of every alternative and criteria is given as $x_{i j}$. The $x_{i j}$ is performance ratings for each alternative $A_{i}(i=1, \ldots, m)$ with respect to criteria $C_{j}(j=1, \ldots, n)$.

Step 2: Normalized decision matrix.

The decision matrix is converted in to the normalized matrix, using the following equation:

$$
p_{i j}=\frac{x_{i j}}{\sum_{j=1}^{m} x_{i j}}
$$

where $i=1,2, \ldots, m$ and $j=1,2, \ldots, n$

Step 3: Weighted normalized decision matrix.

According to the fact that the relative importance of various criteria is not the same and they have different weights, the weight or relative importance of criteria, should be obtained. The criteria weights could be determined in a way that the sum of them become equal to 1 as Eq. (4) shows.

$$
\sum_{j=1}^{n} w_{j}=1
$$

where $w_{j}$ is the weight of the $j$ th criterion.

In this paper $w_{j}$ will be set based on SEA that will be explained in section 2.3. The weighted normalized matrix is obtained based on multiplying the normalized decision matrix by its associated weights. The weighted normalized decision matrix is formed as follow:

$$
V_{i j}=w_{j} \times p_{i j}
$$

where $i=1,2, \ldots, m ; j=1,2, \ldots, n$.

Step 4: Determine positive and negative ideal solution.

The positive ideal solution (PIS) is the best attribute values and the negative ideal solution (NIS) is the worst attribute values in each 
criterion. The PIS and NIS are chosen as follows by Eqs. (6) and (7), respectively:

$$
\begin{aligned}
& V^{+}=\left(V_{1}^{+}, V_{2}^{+}, \ldots, V_{n}^{+}\right) \\
& V^{-}=\left(V_{1}^{-}, V_{2}^{-}, \ldots, V_{n}^{-}\right)
\end{aligned}
$$

Where, for positive attributes (more is better), $V_{j}^{+}$is the maximum values and $V_{j}^{-}$is the minimum values of criterion $j$. while, for negative attributes (less is better), $V_{j}^{+}$is the minimum values and $V_{j}^{-}$is the maximum values of criterion $j$.

Step 5: Calculate distance measure for each alternative to the PIS and NIS.

In this step distance of every alternative from PIS and NIS are calculated as follows:

$$
\begin{aligned}
& D_{i}^{+}=\sqrt{\sum_{j=1}^{n}\left(V_{i j}-V_{i}^{+}\right)^{2}}, i=1,2, \ldots, m .(8) \\
& D_{i}^{-}=\sqrt{\sum_{j=1}^{n}\left(V_{i j}-V_{i}^{-}\right)^{2}}, i=1,2, \ldots, m .(9)
\end{aligned}
$$

Step 6: Calculate closeness coefficient $(C C)$ for every alternative.

Closeness coefficient for every alternative is calculated based on the similarity to the best alternative as follows:

$$
C C_{i}=\frac{d_{i}^{-}}{d_{i}^{+}+d_{i}^{-}}
$$

TOPSIS minimizes the distance to the ideal alternative while maximizing the distance to the worst. So, the alternative with largest $C C_{i}$ is the best one for selection. In fact, descend ranking of $C C_{i}$ determines preference of alternatives. It should be noted that $C C_{i}=1$ if and only if the $i$ th solution is the PIS and $C C_{i}=$ 0 if and only if the $i$ th solution is the NIS.

\subsection{Shannon Entropy approach}

Entropy concept considered as a criterion for the degree of uncertainty in information theory represented by a discrete probability distribution. Based on this concept, SEA evaluates the expected value of a certain message. A mathematical theory of this approach was proposed by Shannon (1948). The steps of this algorithm are as follows (Hafezalkotob, \& Hafezalkotob, 2015).
Step 1) The entropy measure of criteria computes based on following equation:

$$
E_{j}=-k \sum_{i=1}^{m} p_{i j} \ln p_{i j} ; j=1, \ldots, n ;
$$

in which $k=1 / \ln (m)$.

Where $p_{i j}$ are the elements of normalized matrix that obtained by Eq. (3).

Step 2) The distance measure for each criterion obtained as follows:

$$
d_{j}=1-E_{j} ; j=1, \ldots, n
$$

Step 3) Finally, the weight for each criterion determined as follows:

$$
w_{j}=\frac{d_{j}}{\sum_{k=1}^{n} d_{k}} ; j=1, \ldots, n
$$

This paper use SEA to determine weight for each criterion. $w_{j}$ is the weight of $j$ th criteria in decision matrix.

\section{NEW METHOD}

The problem of project ranking in projectbased organizations is very important because of the direct influence on organization incomes. This paper proposes a framework based on FMEA, SEA, and TOPSIS to support organizations to rank project and select the most appropriate ones.

FMEA is utilized for risk management in this study. To provide an efficient and effective project ranking, RPN of T: Time, C: Cost, and Q: Quality, as most important risks of delivering projects, are computed. Then, the criteria weight calculated by SEA and finally TOPSIS method is used for ranking projects based on the decision matrix that the RPNs are criteria and the projects are alternatives.

As shown in Fig. 1, the projects are related to Time, Cost, and Quality of delivering projects as risks. In upper level the risks are related to their occurrence probability, severity of the associated effects, and detection to each failure mode. The aim is to rank projects according to their risks. 


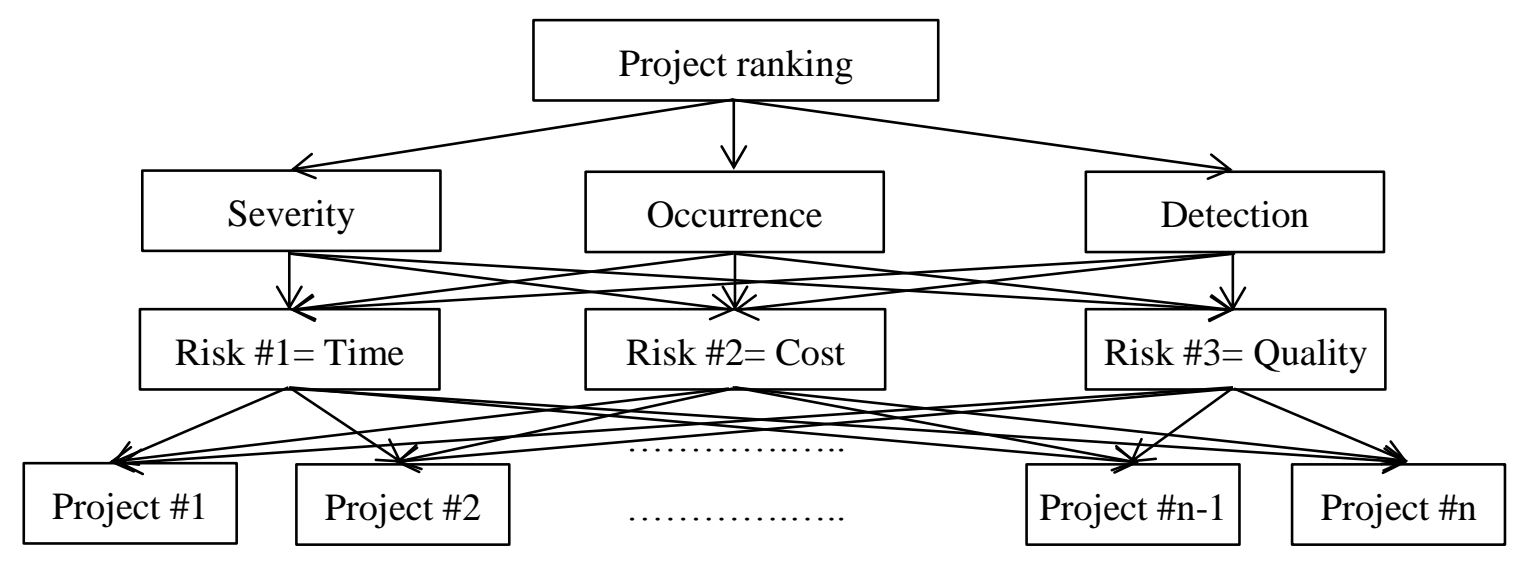

Figure 1: Framework to rank projects

In the following, the steps of the proposed method are further explained.

- Step 1: Calculate RPN for the risks of projects.

The severity, occurrence, and detection for the effects of each failure mode should be determined in the matrix of FMEA. Tree failure modes (risks) included time, cost, and quality of delivering projects are considered for projects ranking in this paper. In fact, a project has better priority in project ranking if has low risk in these three areas. The judgment for risks versus criterion is proposed by experts for each project. The experts are assumed to have the same importance. The FMEA matrix for project $i$ is as follows:

Project $i$ :

$$
\begin{array}{lccc} 
& S & O & D \\
R_{1} \\
R_{2} \\
R_{3}
\end{array} \quad\left(\begin{array}{ccc}
\bar{S}_{i 11} & \bar{S}_{i 12} & \bar{S}_{i 13} \\
\bar{S}_{i 21} & \bar{S}_{i 22} & \bar{S}_{i 23} \\
\bar{S}_{i 31} & \bar{S}_{i 32} & \bar{S}_{i 33}
\end{array}\right)
$$

$i$ index for projects

$j$ index for risk

$k$ index for criterion

Table 1: Linguistic terms for rating risks for project ranking in terms of severity, occurrence, and detection

\begin{tabular}{cc}
\hline Linguistic variable & Index number \\
\hline Very high $(\mathrm{VH})$ & 10 \\
High $(\mathrm{H})$ & 9 \\
Fair $(\mathrm{F})$ & 7 \\
Average $(\mathrm{A})$ & 5 \\
Low $(\mathrm{L})$ & 3 \\
Very low (VL) & 1 \\
\hline
\end{tabular}

$R_{j}$ : $j$ th risk where $j=1$ refers to time, $j=2$ refers to cost and $j=3$ refers to quality.

$R P N_{i j}$ : RPN related to $j$ th risk of project $i$ obtained by Eq. (1).

$\bar{S}_{i j k}: \quad$ Average of decision-maker's assessment in $j$ th risk of $k$ th criteria for project $i$

The RPN demonstrates the failure risk in time, cost, and quality of delivering projects in terms of occurrence, severity, and detection of the failures. To calculate the RPNs of these three risks, each DMs assessed severity, occurrence, and detection value ranging from 1 to 10 based on Table 1. It should be noted that in this paper the sub criteria don't considered for occurrence, severity, and detection for time, cost, and quality. Because this paper aims to propose a main framework of the method for project ranking. It could be considered sub criteria to get better and more accurate result. Finally, RPNs of the failures are calculated by multiplying the occurrence, severity, and detection values as shown in Eq. (1). 
Table 1 presents changing the qualitative variables into quantitative variables. The decision makers use linguistic terms to evaluate risks with respect to each criterion. Depending on the organization in which the model is implemented, the DMs, could be general managers, project managers, planning and control personnel, site engineers, site managers, design engineers, and administrative personnel. They evaluate the projects based on the three risk (Time, Cost, and Quality) in terms of occurrence, severity, and detection of the failures as stated in table 1. The average DMs opinion determine status of risks across each criterion. In fact, the main failure modes are tree risk which might occur in implementation of projects. Risk 1 (Time), Risk 2 (Cost), Risk 3 (Quality) mean organization couldn't deliver project in specified time, cost and determined quality.

- Severity of 1 denotes low risk to deliver project on time/cost/quality to the customer, and a score of 10 denotes high risk to deliver project on time/cost/quality to the customer.

- Occurrence of 1 denotes low probability of the risk happening in delivering project on time/cost/quality to the customer, and a 10 denotes a very high probability of the risk happening in delivering project on time/cost/quality to the customer.

- Detection of 1 denotes a process that will likely NOT catch a failure in delivering project on time/cost/quality to the customer, and a 10 means the process will likely catch a failure in delivering project on time/cost/quality to the customer.

- Step 2: Determine weight for risks by SEA.

The evaluation matrix for project ranking which has $m$ projects and 3 criteria is prepared as follows:

$$
\left.\begin{array}{cccc} 
& R_{1} & R_{2} & R_{3} \\
p_{1} & R P N_{11} & R P N_{12} & R P N_{13} \\
\vdots & \vdots & \vdots & \vdots \\
p_{i} & R P N_{i 1} & R P N_{i 2} & R P N_{i 3} \\
\vdots & \vdots & \vdots & \vdots \\
p_{m} & R P N_{m 1} & R P N_{m 2} & R P N_{m 3}
\end{array}\right)
$$

Where, $p_{i}$ is $i$ th project, $R_{j}$ as mentioned before is the $j$ th risk that $j=1$ is related to time, $j=2$ is related to cost, and finally $j=3$ is related to quality. $R P N_{i j}$ is RPN for $j$ th risk of project $i$ which are computed based on $\bar{S}_{i j k}$ in matrix (14) and Eq. (1) as follows:

$$
R P N_{i j}=\bar{S}_{i j 1} \times \bar{S}_{i j 2} \times \bar{S}_{i j 3}
$$

Based on SEA, first matrix (15) should be normalized by Eq. (3). Then based on Eq. (11) the entropy measure computed for each criterion. The distance measure for each criterion obtained by Eq. (12), and Finally, the weight for each criterion $\left(w_{j}\right)$ obtained by Eq. (13). In fact, SEA calculate the weight, $w_{j}$, of each risk $\left(R_{j}\right)$.

\section{- Step 3: Ranking projects by TOPSIS} method.

In this step, projects ranking is determined by TOPSIS technique under the three criteria included risk of time, risk of cost, and risk of quality for implementation and delivering projects. First, the weight vector and decision matrix are constructed. The weight vector, $w_{j}$, that is the weight of $j$ th criterion $\left(R_{j}\right)$, obtained by SEA as explained in step 2. The decision matrix, as shown in Shannon Entropy step, is based on matrix (14) in step 1 (FMEA step). In fact, the decision matrix is matrix (15) that comes from judgment of decision makers. The normalized decision matrix and weight vector of risks are as follows.

$$
\left.\begin{array}{cccc} 
& R_{1} & R_{2} & R_{3} \\
p_{1} & R P N_{11}^{\prime} & R P N_{12}^{\prime} & R P N_{13}^{\prime} \\
\vdots & \vdots & \vdots & \vdots \\
p_{i} & R P N_{i 1}^{\prime} & R P N_{i 2}^{\prime} & R P N_{i 3}^{\prime} \\
\vdots & \vdots & \vdots & \vdots \\
p_{n} & R P N_{n 1}^{\prime} & R P N_{n 2}^{\prime} & R P N_{n 3}^{\prime}
\end{array}\right)
$$

$$
W=\left[w_{1}, w_{2}, w_{3}\right]
$$

The $R P N_{i j}^{\prime}$ is normalized of $R P N_{i j}$ that calculated by Eq. (3). Based on Eq. (5) the weighted normalized matrix is obtained as follows: 


$$
\left.\begin{array}{cccc} 
& R_{1} & R_{2} & R_{3} \\
p_{1} & V_{R P N_{11}^{\prime}} & V_{R P N_{12}^{\prime}} & V_{R P N_{13}^{\prime}} \\
\vdots & \vdots & \vdots & \vdots \\
p_{i} & V_{R P N_{i 1}^{\prime}} & V_{R P N_{i 2}^{\prime}} & V_{R P N_{i 3}^{\prime}} \\
\vdots & \vdots & \vdots & \vdots \\
p_{n} & V_{R P N_{n 1}^{\prime}} & V_{R P N_{n 2}^{\prime}} & V_{R P N_{n 3}^{\prime}}
\end{array}\right)
$$

Where $V_{R P N_{i j}^{\prime}}=w_{j} * R P N_{i j}^{\prime}$.

According to the fact that the RPN numbers are negative attributes (less is better), the positive ideal solution $\left(V_{j}^{+}\right)$and negative ideal solution $\left(V_{j}^{-}\right)$for each criterion is defined based on Eqs. (6) and (7) as follows:

$$
\begin{aligned}
& V^{+}=\left(V_{1}^{+}, V_{2}^{+}, V_{3}^{+}\right) \\
& V^{-}=\left(V_{1}^{-}, V_{2}^{-}, V_{3}^{-}\right)
\end{aligned}
$$

Where $V_{j}^{+}$is the minimum values and $V_{j}^{-}$is the maximum values of criterion $j$. Then, the distance from PIS $\left(D_{i}^{+}\right)$and NIS $\left(D_{i}^{-}\right)$is calculated for each project by Eqs. (8) and (9) as follows.

$$
D_{i}^{+}=\sqrt{\sum_{j=1}^{3}\left(V_{R P N_{i j}}-V_{j}^{+}\right)^{2}}
$$

$i=1,2, \ldots, n$

$$
D_{i}^{-}=\sqrt{\sum_{j=1}^{3}\left(V_{R P N_{i j}}-V_{j}^{-}\right)^{2}}
$$

$i=1,2, \ldots, n$

Finally, closeness coefficient $\left(C C_{i}\right)$ is calculated based on Eq. (10) as follows:

$$
C C_{i}=\frac{D_{i}^{-}}{D_{i}^{+}+D_{i}^{-}}, i=1, \ldots, n
$$

Project ranking determined according to the closeness coefficient, $C C_{i}$, and the DM could select the best one based on the ranking obtained for projects. The alternative $P_{i}$ with largest $C C_{i}$ is candidate project with least risk.

The flowchart of the proposed new method based on FMEA, SEA, and TOPSIS for project ranking problems is depicted in Fig. 1. The proposed method could be applied in the portfolio of the organizations for all types of projects due to the procedure of combination methods and considering severity, occurrence, and detection in time, cost, and quality that are the most important terms in all projects for portfolio selection. 


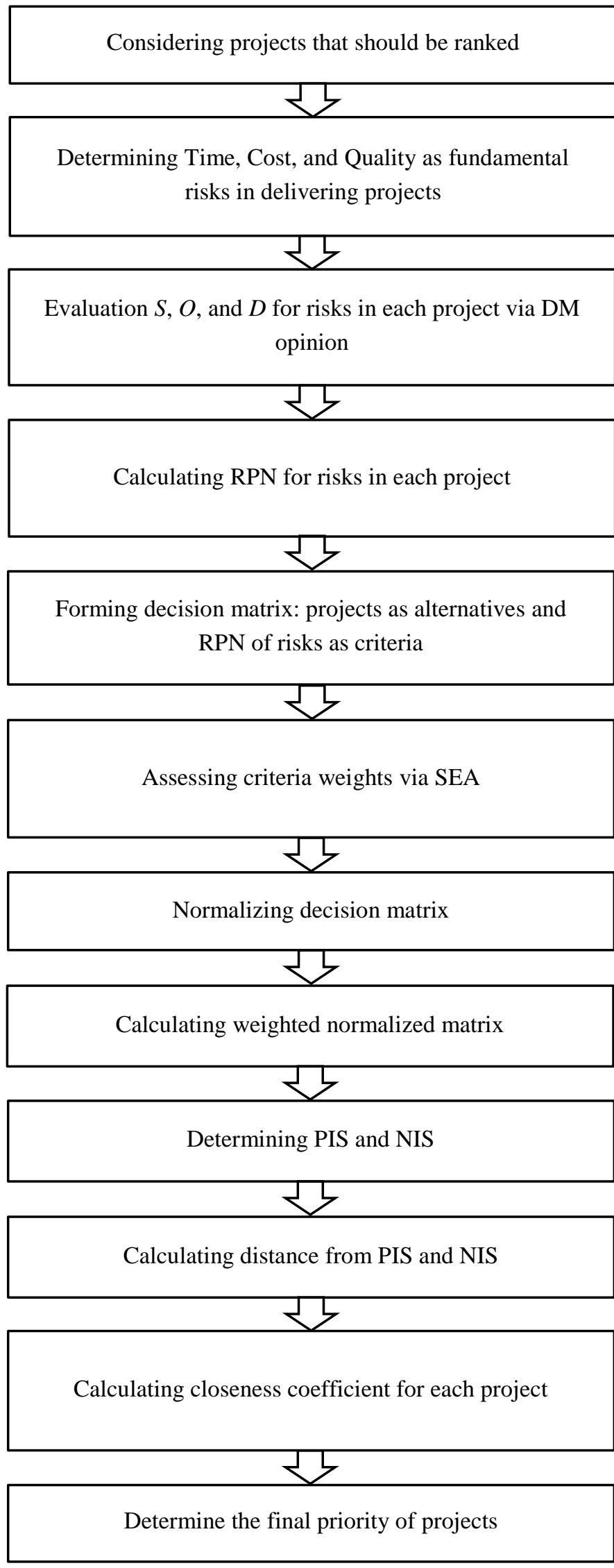

Figure 2: The flowchart of proposed new method for project ranking problem 


\section{NUMERICAL RESULTS}

In this section, a typical project ranking problem is presented to measure the usability and quality of the proposed method in previous section. In the typical example, an organization wants to determine the priority of 5 projects for ranking and selecting them. The organization is a small and project base organization that the proposed method is applied in it. The steps of the proposed method for the typical problem are as follows:
- Step 1: Calculate RPN for projects risks.

Rating of the projects, as shown in table 2, is conducted based on three criteria $(T, C, Q)$, three sub criteria $(S, O, D)$ and four decision makers DM1, DM2, DM3, DM4. Each judgment is expressed with linguistic terms shown in Table 1. Average of four decision makers' opinions determine the combined value of each attribute. Table 2 exhibit the mean of assessment values assigned by the DMs to each attribute.

Table 2: Assessments of projects given by four decision makers.

\begin{tabular}{|c|c|c|c|c|c|c|c|}
\hline Project & Risk & RPN criteria & DM1 & DM2 & DM3 & DM4 & Average \\
\hline \multirow{9}{*}{$P_{1}$} & \multirow{3}{*}{$R_{l}$} & $\mathrm{~S}$ & VH & $\mathrm{H}$ & $\mathrm{H}$ & VH & 9.5 \\
\hline & & $\mathrm{O}$ & $\mathrm{H}$ & VH & $\mathrm{F}$ & $\mathrm{F}$ & 8.25 \\
\hline & & $\mathrm{D}$ & VH & $\mathrm{H}$ & A & $\mathrm{VH}$ & 8.5 \\
\hline & \multirow{3}{*}{$R_{2}$} & $\mathrm{~S}$ & $\mathrm{~F}$ & $\mathrm{~A}$ & $\mathrm{H}$ & $\mathrm{H}$ & 7.5 \\
\hline & & $\mathrm{O}$ & VH & $\mathrm{H}$ & $\mathrm{H}$ & $\mathrm{H}$ & 9.25 \\
\hline & & $\mathrm{D}$ & $\mathrm{H}$ & A & $\mathrm{VH}$ & $\mathrm{F}$ & 7.75 \\
\hline & \multirow{3}{*}{$R_{3}$} & $\mathrm{~S}$ & $\mathrm{~F}$ & $\mathrm{~A}$ & $\mathrm{~L}$ & $\mathrm{~A}$ & 6.5 \\
\hline & & $\mathrm{O}$ & $\mathrm{H}$ & $\mathrm{F}$ & $\mathrm{L}$ & A & 7.5 \\
\hline & & $\mathrm{D}$ & $\mathrm{L}$ & $\mathrm{L}$ & $\mathrm{A}$ & $\mathrm{L}$ & 8 \\
\hline \multirow{9}{*}{$P_{2}$} & \multirow{3}{*}{$R_{I}$} & $\mathrm{~S}$ & $\mathrm{~L}$ & VL & $\mathrm{A}$ & $\mathrm{F}$ & 7.75 \\
\hline & & $\mathrm{O}$ & VL & VL & $\mathrm{L}$ & A & 8.5 \\
\hline & & $\mathrm{D}$ & VL & VL & $\mathrm{L}$ & $\mathrm{L}$ & 9.5 \\
\hline & \multirow{3}{*}{$R_{2}$} & $\mathrm{~S}$ & VL & VL & $\mathrm{L}$ & $\mathrm{A}$ & 8.5 \\
\hline & & $\mathrm{O}$ & $\mathrm{L}$ & VL & VL & VL & 9.75 \\
\hline & & $\mathrm{D}$ & VL & A & $\mathrm{F}$ & $\mathrm{L}$ & 7.75 \\
\hline & \multirow{3}{*}{$R_{3}$} & $\mathrm{~S}$ & $\mathrm{~L}$ & $\mathrm{~L}$ & $\mathrm{~A}$ & $\mathrm{~L}$ & 8 \\
\hline & & $\mathrm{O}$ & VL & A & $\mathrm{L}$ & A & 7.25 \\
\hline & & $\mathrm{D}$ & $\mathrm{L}$ & A & $\mathrm{L}$ & $\mathrm{A}$ & 7 \\
\hline \multirow{9}{*}{$P_{3}$} & \multirow{3}{*}{$R_{l}$} & $\mathrm{~S}$ & $\mathrm{~F}$ & $\mathrm{~F}$ & $\mathrm{~F}$ & $\mathrm{~A}$ & 6.5 \\
\hline & & $\mathrm{O}$ & $\mathrm{H}$ & $\mathrm{F}$ & $\mathrm{H}$ & $\mathrm{H}$ & 8.5 \\
\hline & & $\mathrm{D}$ & $\mathrm{F}$ & $\mathrm{L}$ & $\mathrm{L}$ & A & 7.5 \\
\hline & \multirow{3}{*}{$R_{2}$} & $\mathrm{~S}$ & $\mathrm{~L}$ & $\mathrm{VL}$ & $\mathrm{L}$ & $\mathrm{L}$ & 9.25 \\
\hline & & $\mathrm{O}$ & VL & VL & $\mathrm{L}$ & VL & 9.75 \\
\hline & & $\mathrm{D}$ & A & $\mathrm{L}$ & VL & $\mathrm{L}$ & 8.25 \\
\hline & \multirow{3}{*}{$R_{3}$} & $\mathrm{~S}$ & $\mathrm{~L}$ & $\mathrm{~L}$ & $\mathrm{~A}$ & VL & 8.25 \\
\hline & & $\mathrm{O}$ & VL & $\mathrm{L}$ & $\mathrm{L}$ & $\mathrm{L}$ & 9.25 \\
\hline & & $\mathrm{D}$ & $\mathrm{L}$ & $\mathrm{L}$ & A & $\mathrm{F}$ & 7.5 \\
\hline \multirow{8}{*}{$P_{4}$} & \multirow{3}{*}{$R_{l}$} & $\mathrm{~S}$ & $\mathrm{~F}$ & $\mathrm{H}$ & $\mathrm{A}$ & $\mathrm{H}$ & 7.5 \\
\hline & & $\mathrm{O}$ & $\mathrm{L}$ & $\mathrm{L}$ & $\mathrm{H}$ & $\mathrm{F}$ & 8.5 \\
\hline & & $\mathrm{D}$ & $\mathrm{L}$ & VL & VL & $\mathrm{L}$ & 9.5 \\
\hline & \multirow{3}{*}{$R_{2}$} & $\mathrm{~S}$ & A & $\mathrm{L}$ & $\mathrm{F}$ & $\mathrm{F}$ & 7 \\
\hline & & $\mathrm{O}$ & $\mathrm{L}$ & $\mathrm{L}$ & A & VL & 8.25 \\
\hline & & $\mathrm{D}$ & $\mathrm{F}$ & $\mathrm{F}$ & A & A & 6 \\
\hline & \multirow{2}{*}{$R_{3}$} & $\mathrm{~S}$ & A & $\mathrm{A}$ & $\mathrm{L}$ & $\mathrm{F}$ & 6.5 \\
\hline & & $\mathrm{O}$ & $\mathrm{L}$ & $\mathrm{L}$ & VL & VL & 9.5 \\
\hline
\end{tabular}




\begin{tabular}{cccccccc}
\hline & & $\mathrm{D}$ & $\mathrm{H}$ & $\mathrm{H}$ & $\mathrm{F}$ & $\mathrm{H}$ & 8.5 \\
\hline \multirow{3}{*}{$R_{l}$} & $\mathrm{~S}$ & $\mathrm{H}$ & $\mathrm{F}$ & $\mathrm{VH}$ & $\mathrm{VH}$ & 9 \\
& & $\mathrm{O}$ & $\mathrm{A}$ & $\mathrm{F}$ & $\mathrm{L}$ & $\mathrm{F}$ & 7 \\
& & $\mathrm{D}$ & $\mathrm{L}$ & $\mathrm{L}$ & $\mathrm{A}$ & $\mathrm{A}$ & 7 \\
\cline { 3 - 7 }$P_{5}$ & $R_{2}$ & $\mathrm{~S}$ & $\mathrm{VL}$ & $\mathrm{L}$ & $\mathrm{A}$ & $\mathrm{VL}$ & 8.5 \\
& & $\mathrm{O}$ & $\mathrm{F}$ & $\mathrm{F}$ & $\mathrm{L}$ & $\mathrm{A}$ & 7 \\
& & $\mathrm{D}$ & $\mathrm{VL}$ & $\mathrm{L}$ & $\mathrm{L}$ & $\mathrm{L}$ & 9.25 \\
\cline { 3 - 8 } & & $\mathrm{S}$ & $\mathrm{A}$ & $\mathrm{L}$ & $\mathrm{L}$ & $\mathrm{L}$ & 8 \\
& & $\mathrm{O}$ & $\mathrm{A}$ & $\mathrm{VL}$ & $\mathrm{VL}$ & $\mathrm{F}$ & 8 \\
& $R_{3}$ & $\mathrm{D}$ & $\mathrm{L}$ & $\mathrm{L}$ & $\mathrm{VL}$ & $\mathrm{VL}$ & 9.5 \\
\hline
\end{tabular}

The failure mode analysis of projects is shown in Table 3. Based on the DM's assessment in table 2, RPN of each risk is calculated by Eq.
(16) as shown in Table 3. As stated before, the risks are: $R_{1}$ : Time, $R_{2}$ : Cost, and $R_{3}$ : Quality.

Table 3: The FMEA matrix.

\begin{tabular}{cccccc}
\hline Project & Risk & $\mathrm{S}$ & $\mathrm{O}$ & $\mathrm{D}$ & $\mathrm{RPN}$ \\
\hline \multirow{3}{*}{$P_{1}$} & $R_{I}$ & 9.5 & 8.25 & 8.5 & 666.188 \\
& $R_{2}$ & 7.5 & 9.25 & 7.75 & 537.656 \\
& $R_{3}$ & 6.5 & 7.5 & 8 & 390 \\
\hline \multirow{3}{*}{$P_{2}$} & $R_{I}$ & 7.75 & 8.5 & 9.5 & 625.813 \\
& $R_{2}$ & 8.5 & 9.75 & 7.75 & 642.281 \\
& $R_{3}$ & 8 & 7.25 & 7 & 406 \\
\hline \multirow{3}{*}{$P_{3}$} & $R_{1}$ & 6.5 & 8.5 & 7.5 & 414.375 \\
& $R_{2}$ & 9.25 & 9.75 & 8.25 & 744.047 \\
& $R_{3}$ & 8.25 & 9.25 & 7.5 & 572.344 \\
\hline \multirow{3}{*}{$P_{4}$} & $R_{I}$ & 7.5 & 8.5 & 9.5 & 605.625 \\
& $R_{2}$ & 7 & 8.25 & 6 & 346.5 \\
& $R_{3}$ & 6.5 & 9.5 & 8.5 & 524.875 \\
\hline \multirow{3}{*}{$P_{5}$} & $R_{I}$ & 9 & 7 & 7 & 441 \\
& $R_{2}$ & 8.5 & 7 & 9.25 & 550.375 \\
& $R_{3}$ & 8 & 8 & 9.5 & 608 \\
\hline
\end{tabular}

- Step 2: Determine weight for RPN of risks by SEA.

Based on the RPN of risks calculated in Table 3 , the decision matrix for project ranking formed as shown in Table 4. The decision matrix consists of five projects as alternatives and three RPN of risks including RPN of time (RPN1), RPN of cost (RPN2), and RPN of quality $(R P N 3)$ as criteria.

Table 4: Decision matrix

\begin{tabular}{cccc}
\hline Project & $R P N 1$ & $R P N 2$ & $R P N 3$ \\
\hline$P_{1}$ & 666.1875 & 537.65625 & 390 \\
$P_{2}$ & 625.8125 & 642.28125 & 406 \\
$P_{3}$ & 414.375 & 744.046875 & 572.34375 \\
$P_{4}$ & 605.625 & 346.5 & 524.875 \\
$P_{5}$ & 441 & 550.375 & 608 \\
\hline 60 & & &
\end{tabular}

The information in table 4 can be normalized using Eq. (3) as displayed in Table 5. The normalized decision matrix is used for calculating weights of RPNs by SEA in step 2, and also used for ranking projects by TOPSIS in step 3.

Table 5: The normalized Decision matrix

\begin{tabular}{cccc}
\hline Project & $R P N 1$ & $R P N 2$ & $R P N 3$ \\
\hline$P_{1}$ & 0.24198602 & 0.19060016 & 0.15592399 \\
$P_{2}$ & 0.2273202 & 0.22768992 & 0.16232087 \\
$P_{3}$ & 0.15051762 & 0.26376603 & 0.22882595 \\
$P_{4}$ & 0.21998729 & 0.12283491 & 0.2098477 \\
$P_{5}$ & 0.16018888 & 0.19510898 & 0.2430815 \\
\hline \multicolumn{3}{c}{} \\
\end{tabular}


Based on information in table $5, E_{j}$ and $d_{j}$ were calculated using Eqs. (11) and (12), respectively, as shown in Table 6. By applying Eq. (13) the general Shannon entropy weight $\left(w_{j}\right)$ was obtained in Table 6 . In fact, the last row of table 6 belongs to the $w_{j}$, shows the relative importance of each RPNs as criteria.

Table 6: The criteria weight by SEA

\begin{tabular}{cccc}
\hline Project & $R P N 1$ & $R P N 2$ & $R P N 3$ \\
\hline$E_{j}$ & 0.98891816 & 0.98221 & 0.9903 \\
$d_{j}$ & 0.01108184 & 0.01779 & 0.0097 \\
$w_{j}$ & 0.28726933 & 0.46121 & 0.25152 \\
\hline
\end{tabular}

- Step 3: Ranking projects by TOPSIS.

After obtaining the weights of RPNs by SEA in table 6, the weighted normalized decision matrix shown in Table 7 can be formed by Eq. (5).

Table 7: The weighted normalized matrix

\begin{tabular}{cccc}
\hline Project & $R P N 1$ & $R P N 2$ & $R P N 3$ \\
\hline$P_{1}$ & 0.06951516 & 0.08790605 & 0.03921864
\end{tabular}

\begin{tabular}{lccc}
$P_{2}$ & 0.06530212 & 0.10501209 & 0.04082761 \\
$P_{3}$ & 0.0432391 & 0.12165063 & 0.05755524 \\
$P_{4}$ & 0.0631956 & 0.05665227 & 0.05278175 \\
$P_{5}$ & 0.04601735 & 0.08998555 & 0.06114085 \\
\hline
\end{tabular}

PIS and NIS defined in Eqs. (6) and (7) are used to determine the positive and negative ideal solution. According to the fact that the RPNs are negative-type criteria, Eq. (7) used for calculating the PIS and NIS as revealed in Table 8.

Table 8: The PIS and NIS of criteria

\begin{tabular}{cccc}
\hline Project & RPN1 & RPN2 & RPN3 \\
\hline$V_{j}^{+}$ & 0.0432391 & 0.05665 & 0.03922 \\
$V_{j}^{-}$ & 0.06951516 & 0.12165 & 0.06114 \\
\hline
\end{tabular}

Table 9 shows the final priority of projects based on the proposed model. In this table the Euclidean distances of each projects to the ideal solution is calculated by Eqs. (8) and (9). Then a total score or relative closeness coefficient for each project $\left(C C_{i}\right)$ is obtained by using Eq. (10) as shown in Table 9.

Table 9: The priority ranking of the projects by TOPSIS

\begin{tabular}{ccccc}
\hline Project & $D_{i}{ }^{+}$ & $D_{i}{ }^{-}$ & $C C_{i}$ & Final rank \\
\hline$P_{1}$ & 0.04083173 & 0.0402403 & 0.49635229 & 3 \\
$P_{2}$ & 0.0531793 & 0.0265936 & 0.33336616 & 4 \\
$P_{3}$ & 0.06753531 & 0.0265196 & 0.28195857 & 5 \\
$P_{4}$ & 0.02412924 & 0.0658377 & 0.73179873 & 1 \\
$P_{5}$ & 0.03999262 & 0.0394313 & 0.49646606 & 2 \\
\hline
\end{tabular}

The closeness coefficient was presented as an index for decision making. As shown in Table 9 , projects $P_{4}, P_{5}, P_{1}, P_{2}$, and $P_{3}$ are ranked from first to fifth, respectively. This result shows that according to the proposed method, $P_{4}$ has a highest priority for project selection and its closeness coefficient $\left(C C_{4}\right)$ is equal to 0.73179873 .

\section{CONCLUSIONS}

This study provides a project ranking tool by considering hybrid methodology of FMEA, SEA, and TOPSIS to handle efficiently project ranking decisions. The proposed model is reliable and applicable because of considering fundamental risks of delivering projects as criteria including time, cost, and quality.
The project ranking method proposed in this paper is a technique for organizations to rank the projects and select the best candidate by multi-criteria approach that using linguistic preferences. The FMEA is used to analyze the risks of delivering projects. The RPN of risks are determined as the criteria and the weights of them calculated by SEA. Finally, TOPSIS method is used to obtain final ranking of projects.

In fact, this study proposed a new approach for project ranking by presenting a new framework. In this framework, time, cost, and quality recommended as fundamental risks of delivering projects. In the future research, other risks could be considered as criteria and also sub criteria could be determined for time, cost and quality. In, fact, the number of criteria and 
increasing them could be considered for future research. Comparing the results obtained by the method applied in this study with other methods is the other area for future research.

\section{REFERENCES}

Buchanan, J., \& Vanderpooten, D. (2007). Ranking projects for an electricity utility using ELECTRE III. International Transactions in Operational Research. 14, pp. 309-323.

Carbone, T. A., \& Tippett, D. D. (2004). Project Risk Management Using the Project Risk FMEA. Engineering Management Journal. 16(4).

Cesarone, F., Scozzari, A., \& Tardella, F. (2019). An optimization-diversification approach to portfolio selection. Journal of Global Optimization. 76, pp. 245-265.

Daneshvar, R. B., \& Erol, S. (2012). Selecting the Best Project Using the Fuzzy ELECTRE Method. Mathematical Problems in Engineering, Article ID 790142, 12 pages doi:10.1155/2012/790142.

Goletsis, Y., Psarras, J., \& Samouilidis, J. E. (2003). Project Ranking in the Armenian Energy Sector Using a Multicriteria Method for Groups. Annals of Operations Research. 120, pp. 135-157.

Hafezalkotob, A., \& Hafezalkotob, A. (2015). Extended MULTIMOORA method based on Shannon entropy weight for materials selection. Journal of Industrial Engineering International. doi: 10.1007/s40092-015-0123-9.

Li, X., Wang, Y., Yan, Q., \& Zhao, X. (2018). Uncertain mean-variance model for dynamic project portfolio selection problem with divisibility. Fuzzy Optimization and Decision Making, doi: 10.1007/s10700-018-9283-6.

Ma, J., Harstvedt, J. D., Jaradat, R., \& Smith, B. (2020). Sustainability driven multicriteria project portfolio selection under uncertain decision-making environment. Computers \& Industrial Engineering. 140, 106236.

Mahmoodzadeh, S., Shahrabi, J., Pariazar, M., \& Zaeri, M. S. (2007). Project Selection by Using Fuzzy AHP and TOPSIS Technique. International Journal of
Industrial and Manufacturing

Engineering, 1(6).

Mandić, D., Jovanović, P., \& Bugarinović, M. (2014). Two-phase model for multicriteria project ranking: Serbian Railways case study. Transport Policy. 36, pp. 88104.

Oukil, A., \& Govindaluri, S. M. (2020). A hybrid multi-attribute decision-making procedure for ranking project proposals: A historical data perspective. Managerial and decision economics. 41(3), pp. 461472.

Samaras, G. D., Gkanas, N. I., \& Vitsa, K. C. (2014). Assessing risk in Dam projects using AHP and ELECTRE I. International Journal of Construction Management. 14(4), pp. 255-266.

Selim, H., Yunusoglu, M. G., \& Yilmaz, B. Ş. (2016). A Dynamic Maintenance Planning Framework Based on Fuzzy TOPSIS and FMEA: Application in an International Food Company. Quality and Reliability Engineering International. 32, pp. 795-804.

Pakdin, A. M. (2010). Project selection for oilfields development by using the AHP and fuzzy TOPSIS methods. Expert Systems with Applications. 37, pp. 6218-6224.

Pérez, F., Gómez, T., Caballero, R., \& Liern, V. (2018). Project portfolio selection and planning with fuzzy constraints. Technological Forecasting and Social Change. 131, pp. 117-129.

Puerto, J., Rodríguez-Madrena, M., \& Scozzari, A. (2020). Clustering and portfolio selection problems: A unified framework, Computers \& Operations Research. 117, 104891.

Tavana, M., Keramatpour, M., SantosArteagad, F. J., \& Ghorbaniane, E. (2015). A fuzzy hybrid project portfolio selection method using Data Envelopment Analysis, TOPSIS and Integer Programming. Expert Systems with Applications. 42, pp. 8432-8444.

Taylan, O., Bafail, A. O., Abdulaal, R. M. S., \& Kabli, M. R. (2014). Construction projects selection and risk assessment by fuzzy AHP and fuzzy TOPSIS methodologies. Applied Soft Computing. 17, pp. 105-116. 
Toljaga-Nikolić, D., Todorović, M., \& Bjelica, D. (2018). Application of the FMEA technique in a project risk analysis. European Project Management Journal. 8(2), pp. 36-42.

Vahdani, B., Salimi, M., \& Charkhchian, M. (2015). A new FMEA method by integrating fuzzy belief structure and TOPSIS to improve risk evaluation process. International Journal of Advanced Manufacturing Technology. 77, pp. 357-368.

Walczak, D., \& Rutkowska, A. (2017). Project rankings for participatory budget based on the fuzzy TOPSIS method. European Journal of Operational Research. 260, pp. 706-714.

Won, J. H., \& Kim, S. J. (2020). Robust tradeoff portfolio selection. Optimization and Engineering, doi: 10.1007/s11081-02009485-z.

Yazdani-Chamzini, A., Haji, Y. S., \& Mahmoodian, M. (2013). Risk ranking of tunnel construction projects by using the ELECTRE technique under a fuzzy environment. International Journal of Management Science and Engineering Management. 8(1), pp. 1-14. 